\title{
Experience with OK-432 in lymphatic vascular malformations in a hospital from northern Mexico
}

\author{
Jorge A. Cantú-Reyes ${ }^{1,2}$, Erik A. Mier-Escurra ${ }^{1,2 *}$, Joel Cázares-Rangel ${ }^{1}$, Julieta Rodríguez-De Ita², \\ Jan Lammel-Lindemann², Luis F. Rendón-García² and Boris J. Chacón-López ${ }^{2}$ \\ ${ }^{1}$ Hospital Regional de Alta Especialidad Materno Infantil; ${ }^{2}$ Escuela de Medicina, Tecnológico de Monterrey. Monterrey, Nuevo León, Mexico
}

\begin{abstract}
Background: Lymphatic vascular malformations (LVM) or formerly called lymphangiomas are congenital malformations present in about 1 out of 6,000 to 16,000 births. The most relevant classification system for lymphangioma management is based on the size of the cysts. Spontaneous resolution is uncommon; thus, expectant management is not recommended. The classic treatment is excisional surgery, but it can affect adjacent structures or have relapses, so, sclerosing substances like OK432 are being studied. The majority of the studies are in a small sample of patients and are from Japan; the largest studies in Mexico are focused on specific lesions (macrocystic) or a determined anatomical region. To date, there are no studies of the population of the north of Mexico. Methods: The experience with OK-432 was described through a retrospective, descriptive study in patients with LVM, from 2011 to 2016, in a reference hospital of northern Mexico. Results: A total of 26 patients with LVM were treated with OK-432. The majority of the lesions were macrocystic (69\%), microcystic (19\%) and mixed (12\%). From the total number of patients, 11 fully healed, and $72 \%$ of the study population had $>50 \%$ reduction in lesion size with only two applications. There were no recurrences. Complications were reported in two patients who had skin hyperpigmentation. Conclusions: OK-432 probed to be an effective treatment for LVM in a reference hospital in the north of Mexico.
\end{abstract}

Key words: OK-432. Lymphangioma. Sclerotherapy.

\section{Experiencia con OK-432 en malformaciones vasculares linfáticas en un hospital del norte de México}

\section{Resumen}

Introducción: Las malformaciones vasculares linfáticas (MVL), anteriormente llamadas linfangiomas, son malformaciones congénitas que se presentan en uno de cada 6,000 a 16,000 nacimientos. El sistema de clasificación más útil para el manejo del linfangioma se basa en el tamaño de los quistes. La resolución espontánea es infrecuente, por lo que el tratamiento expectante no se recomienda. El tratamiento clásico es la cirugía de escisión, pero puede afectar a estructuras vecinas o haber recidivas, por lo que se empezaron a estudiar sustancias esclerosantes, como el OK-432. La mayoría de los estudios incluyen pocos pacientes; los más grandes realizados en México se enfocan a lesiones específicas (macroquísticas) o únicamente a una región anatómica. Hasta la fecha, no existen estudios del uso de este fármaco en la población del norte

Correspondence:

*Erik Antonio Mier-Escurra

E-mail: erik_mier@hotmail.com
Date of reception: 15-05-2017

Date of acceptance: 20-10-2017

DOI: 10.24875/BMHIME.M18000027
Available online: 10-08-2018 Bol Med Hosp Infant Mex. 2018;75:76-80 www.bmhim.com 
de México. Método: Se describe la experiencia con OK-432 mediante un estudio retrospectivo, descriptivo, en los pacientes con MVL, de 2011 a 2016, en un hospital de referencia del norte de México. Resultados: Veintiséis pacientes con MVL recibieron tratamiento con OK-432. La mayoría fueron macroquísticos (69\%), microquísticos (19\%) y mixtos (12\%). Del total de pacientes, 11 presentaron curación total. El $72 \%$ de la población estudiada tuvo una reducción de > 50\% del tamaño de las lesiones con solo dos aplicaciones de tratamiento; no se presentaron recidivas. Se reportaron complicaciones en dos pacientes (hiperpigmentación de la piel). Conclusiones: El manejo con OK-432 demostró ser efectivo para el tratamiento de las MVL en un hospital de referencia del norte de México.

Palabras clave: OK-432. Linfangioma. Escleroterapia.

\section{Introduction}

Lymphatic vascular malformations (LVM) or formerly called lymphangiomas are congenital malformations present in 1 out of 6,000 to 16,000 births. Sixty percent of these malformations can be observed on physical examination at birth, and $80-90 \%$ are detected when the patient reaches the age of two ${ }^{1}$. These malformations are composed of lymphatic channels and cystic spaces of variable size. The head-and-neck region is the most frequently affected, but they can occur throughout the body. Although they are histologically benign, these lesions can extend to the surrounding organs and cause life-threatening complications ${ }^{2}$.

The International Society for the Study of Vascular Anomalies (ISSVA) classifies lymphatic malformations as macrocystic, microcystic, and mixed; however, there is no uniform consensus in this regard ${ }^{1}$.

The most useful classification system for the management of lymphangiomas is based on the size of the cysts: macrocystic (cysts $>2 \mathrm{~cm}$ ), microcystic (cysts < $2 \mathrm{~cm}$ ) or mixed (when $>50 \%$ of the total disease composition is macrocystic $)^{3}$. This classification has clinical implications since microcystic lymphangiomas seem to be less responsive to clinical treatments, such as sclerotherapy ${ }^{4}$.

In most of the cases, the diagnosis of lymphangiomas is straightforward. The tumors are characterized by the presence of a soft, rubbery, compressible, septate and poorly defined mass. Imaging studies, ultrasound, computed axial tomography or magnetic resonance imaging can help with the diagnosis or can be used to determine the relationship of the lesion with adjacent structures and guide during the surgical act or drug administration ${ }^{5}$.

These lymphatic malformations present spontaneous resolution very infrequently (up to $6 \%)^{6}$, so expectant treatment is not recommended ${ }^{1}$. The standard first choice treatment is surgical excision, although its disadvantages include actual or potential aesthetic damage, or in the worst case, vascular or nervous compromise associated with the lesion, which leads to a partial excision and recurrence in up to $50 \%$ cases $^{7,8}$. Consequently, other products such as sirolimus, a drug used as an immunosuppressant that is still under investigation as a treatment for $\mathrm{LVM}^{9}$, or sclerosing agents, including sodium morrhuate, dextrose, tetracycline, doxycycline, bleomycin, an alcoholic solution of zein (Ethibloc ${ }^{\circledR}$ ) and OK-432 have been used. According to Okazaki et al., Ogita was the first to publish the use of OK-432 in lymphangiomas ${ }^{2}$. OK-432 is derived from a low-virulence strain of Streptococcus pyogenes treated with potassium penicillin $\mathrm{G}$. The main advantage of OK-432 over other sclerosing agents is the absence of perilesional fibrosis, which is why it has been proposed as the first line treatment for LVM over the past few years².

There is little worldwide literature on the management of LVM with OK-432 due to their low frequency and that it only affects pediatric patients. In addition, there is no experimental animal model of LVM. For this reason, most studies have been done with a few patients, and the most important ones took place in Japan. The largest studies conducted in Mexico are on specific lesions, such as the macrocystic type, or are focused only on a particular anatomical region, such as the tongue. Regarding the population of northern Mexico, there are no published works to the present date. In the current study, the experience with OK-432 in patients with LVM in a reference hospital in northern Mexico is described.

\section{Methods}

A review of the LVM clinic records of a reference hospital in the northern area of the country was conducted. Pediatric patients diagnosed with lymphangioma who have been treated with OK-432 in a period of 6 years (2011 to 2016) were analyzed. Patients allergic to penicillin were not considered candidates for OK432. Thirty-five LVM cases with clinical diagnosis confirmed by radiological studies were found. Of these patients, nine were eliminated because they did not 
show up for the treatment administration, did not attend follow-up visits or presented spontaneous healing $(n=3)$. We analyzed the results of 26 patients who were treated with one or more OK-432 administrations and were followed-up in the hospital. OK-432 was administered in the LVM according to the protocol established by Ogita et al. ${ }^{8}$ : the $1 \mathrm{KE}$ presentation OK-432 was used, and it was diluted in injectable water to maintain a density of $0.1 \mathrm{KE} / \mathrm{ml}$. Each patient was anesthetized, and the affected area was cleaned and disinfected. According to the accessibility of the LVM, support ultrasound was used for OK-432 administration. Most of the cystic fluid was aspirated using a syringe, and the same volume $(\mathrm{ml})$ of the prepared OK-432 solution was injected. The maximum administrated amount of medication was $20 \mathrm{ml}$.

After the OK-432 administration, every patient had to remain hospitalized for 24 hours at least, for the management of potential adverse effects, such as fever, systemic inflammatory response, and anaphylaxis. The patients were scheduled three weeks later for evaluation; if a new dose was required, the patient was rescheduled three weeks later for a new OK-432 administration. From the moment of healing, the patient was given a five-year follow-up.

Data analysis was performed by dumping the data into the MS Excel ${ }^{\circledR}$ database and plotting it with the same program. Patient records were reviewed concerning the location, type of lesion, the presence of complications or sequelae, number of infiltrations, diagnostic imaging studies and size.

Lymphangiomas were classified by imaging studies as macrocystic, microcystic or mixed. The response to treatment was classified as complete when LVM presented full healing; favorable, when LVM showed a reduction of more than $50 \%$ of its size; unfavorable when it showed less than $50 \%$ reduction; and without response when there was no decrease in the LVM size. The response of the LVM to OK-432 was evaluated clinically and radiologically.

\section{Results}

Twenty-six patients with LVM treated with OK-432 were followed-up: $62 \%$ of them were males. The malformations were found in the neck (54\%), thorax (15\%), legs $(15 \%)$, head $(4 \%)$, abdomen $(4 \%)$, and arms $(4 \%)$. The distribution by lesion type was macrocystic in $69 \%$, microcystic in $19 \%$, and mixed in $12 \%$. The initial LVM size was on average $6 \mathrm{~cm}$ long (with a minimum of $1 \mathrm{~cm}$ and a maximum of $16 \mathrm{~cm}$ ) and $4.6 \mathrm{~cm}$ width (with

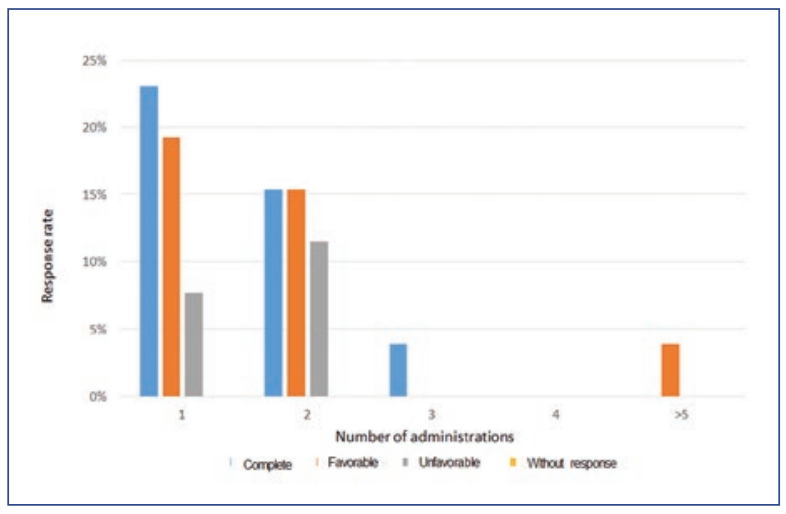

Figure 1. Type of response according to the number of OK-432 administrations and the percentage of the population under study.

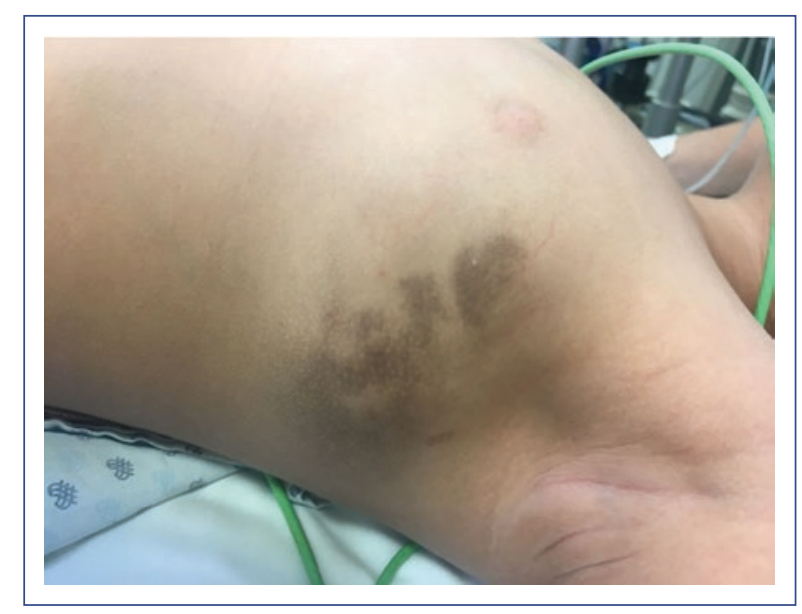

Figure 2. Complication of $0 \mathrm{~K}-432$ treatment: dermatosis characterized by a poorly defined hyperpigmented area of the skin.

a minimum of $0.55 \mathrm{~cm}$ and a maximum of $14 \mathrm{~cm}$ ). The average number of OK-432 administrations was 1.6 (a minimum of one and a maximum of five) (Figure 1). Complications that occurred after OK-432 treatment were manifested as skin hyperpigmentation in two patients (Figure 2).

Of the 26 studied patients, $72 \%$ presented a complete or favorable response after only one or two OK-432 administrations; $4 \%$ of patients showed a complete response after the third application and $4 \%$ presented a favorable response after the fifth administration (Figure 1).

All patients responded to the treatment. Eleven patients (42.3\%) exhibited a complete response with the full healing of the lesion. Of the macrocystic LVM, 33\% presented full healing, $60 \%$ of the microcystic type and 
Table 1. Treatment response of each lymphatic vascular malformation type.

\begin{tabular}{|l|c|c|c|c|}
\hline Lymphangioma type vs. response* & Complete & Favorable & Unfavorable & Without response \\
\hline Macrocystic & $6 / 18(33 \%)$ & $10 / 18(56 \%)$ & $2 / 18(11 \%)$ & $0 / 18(0 \%)$ \\
\hline Microcystic & $3 / 5(60 \%)$ & $0 / 5(0 \%)$ & $2 / 5(40 \%)$ & $0 / 5(0 \%)$ \\
\hline Mixed & $2 / 3(67 \%)$ & $0 / 3(0 \%)$ & $1 / 3(33 \%)$ & $0 / 3(0 \%)$ \\
\hline
\end{tabular}

*Total number per type of lymphangioma (percentage)

Table 2. Type of response of lymphatic vascular malformations in each anatomical location.

\begin{tabular}{|l|c|c|c|c|}
\hline Lymphangioma location vs. response* & Complete & Favorable & Unfavorable & Without response \\
\hline Head & $1 / 2(50 \%)$ & $1 / 2(50 \%)$ & $0 / 2(0 \%)$ & $0 / 2(0 \%)$ \\
\hline Neck & $8 / 14(57 \%)$ & $1 / 14(7 \%)$ & $5 / 14(36 \%)$ & $0 / 14(0 \%)$ \\
\hline Thorax & $0 / 4(0 \%)$ & $4 / 4(100 \%)$ & $0 / 4(0 \%)$ & $0 / 4(0 \%)$ \\
\hline Abdomen & $0 / 1(0 \%)$ & $1 / 1(100 \%)$ & $0 / 1(0 \%)$ & $0 / 1(0 \%)$ \\
\hline Legs & $1 / 4(25 \%)$ & $3 / 4(75 \%)$ & $0 / 4(0 \%)$ & $0 / 4(0 \%)$ \\
\hline Arms & $1 / 1(100 \%)$ & $0 / 1(0 \%)$ & $0 / 1(0 \%)$ & $0 / 1(0 \%)$ \\
\hline
\end{tabular}

*Total number per anatomical location (percentage)

$67 \%$ of the mixed type. Moreover, $38.5 \%$ of patients exhibited a favorable response, led by macrocystic LVM, and $19.2 \%$ of patients had an unfavorable response, led by microcystic LVM; therefore, lesions presented great variability depending on the patient (Table 1).

According to the anatomical location, LVM presented in the arm showed full healing; however, only one patient presented LVM in this location. Conversely, 57\% of neck lesions showed full healing and $50 \%$ of head lesions as well. The healing percentage was obtained according to the anatomical location and the type of treatment response (Table 2).

\section{Discussion}

In this study, which represents a demographic sample from the north of the country, a higher percentage of LVM was observed in males $(62 \%)$, which differs from other studies that show a similar proportion in both genders $^{1-3,10}$. The neck-and-head region was the most common LVM anatomical location, and the most frequent type was macrocystic. These data, besides the size of the lesions, reveal similar results to other studies previously conducted $d^{1,2,10}$. In the present work, the average number of OK-432 administrations was 1.6, a lower result than the reported in most of the studies ${ }^{2,10}$.
Complications occurred in two patients, manifested as skin hyperpigmentation. The results differ when compared with other published studies ${ }^{1,2,10}$ since other works consider fever, edema, discomfort, and hyperthermia in the area of the lesion as complications. In this study, as in other reports ${ }^{3}$, these effects were defined as secondary reactions.

Of the 26 patients who received OK- $432,72 \%$ presented a complete or favorable response after one or two administrations. These results are similar to those observed in other studies ${ }^{1,2}$. Most studies conclude that if there is no response after the first dose, it is less likely that this will be achieved with subsequent doses ${ }^{1,2}$. However, if the expected response was not obtained after the first dose, the OK-432 can still be administered in later appointments without an established maximum administration limit. In the study by Okazaki et al., one of the most important studies carried out in Japan, they reported up to 23 administrations to the same patient ${ }^{2}$. Therefore, many of the patients who have not achieved yet full healing will continue with subsequent applications.

In all the patients to whom OK-432 was applied, there was a decrease in the lesion size; however, the quality of the response obtained was very variable, and no significant difference was found between the LVM types. In the majority of studies, the macrocystic lesion is the one with the best response after OK-432 administration ${ }^{1-3}$. 
In the study conducted by Mejía et al., in which macrocystic LVM were specifically treated, its high effectiveness in Mexican patients was described ${ }^{10}$. In some studies, microcystic lesions have a very poor respon$\mathrm{se}^{1-3}$, and in other works, no differences were found in the response depending on the lesion ${ }^{11}$. However, in the current study, $33 \%$ of the macrocystic lesions, $60 \%$ of the microcystic lesions and $67 \%$ of the mixed ones presented full healing, although the macrocystic LVM presented more favorable responses and less unfavorable than the others. In addition to the response variability, there is a great difference in the number of patients with the different types of malformations: 18 macrocystic, five microcystic and three mixed.

Depending on the anatomical location, the results were very variable concerning the response to OK-432 treatment, without presenting a significant difference. In other studies, where this comparison was also made, the result was not significant ${ }^{2}$, or there was no difference concerning the lesion location and the effect of OK432 treatment $^{1}$.

One of the study limitations was its retrospective nature, besides that only OK-432 treatment was administered. Therefore, a direct comparison with other treatments cannot be made.

Based on these findings, we can conclude that regardless of the type, size and anatomical location, all patients with LVM presented an improvement or healing of the lesion. Consequently, the OK-432 treatment proved to be an effective procedure for LVM in a reference hospital in northern Mexico.

\section{Ethical disclosures}

Protection of human and animal subjects. The authors state that the procedures followed were conformed to the ethical standards of the committee on responsible human experimentation and by the World Medical Association and the Declaration of Helsinki.

Confidentiality of data. The authors declare that they have followed the protocols of their work center on the publication of patient data.
Right to privacy and informed consent. The authors have obtained the written informed consent of the patients or subjects mentioned in the article. The corresponding author is in possession of this document.

\section{Acknowledgments}

Thanks are due to the team of doctors and nurses of the Hospital Regional Materno Infantil de Alta Especialidad for their support and participation in the evaluation of the patients.

\section{Funding}

None.

\section{Conflicts of interest}

The authors declare no conflicts of interest.

\section{References}

1. de Oliveira Olímpio H, Bustorff-Silva J, de Oliveira Filho AG, de Araujo KC. Cross-sectional study comparing different therapeutic modalities for cystic lymphangiomas in children. Clinics. 2014;69:505-8.

2. Okazaki T, Iwatani S, Yanai T, Kobayashi H, Kato Y, Marusasa T, et al. Treatment of lymphangioma in children: our experience of 128 cases. J Pediatr Surg. 2007;42:386-9.

3. Giguère CM, Bauman NM, Sato Y, Burke DK, Greinwald JH, Pransky S, et al. Treatment of lymphangiomas with OK-432 (Picibanil) sclerotherapy: a prospective multi-institutional trial. Arch Otolaryngol Head Neck Surg. 2002;128:1137-44.

4. Wassef M, Blei F, Adams D, Alomari A, Baselga E, Berenstein A, et al. Vascular anomalies classification: recommendations from the International Society for the Study of Vascular Anomalies. Pediatrics. 2015; 136:2014-3673.

5. Grasso D, Pelizzo G, Zocconi E, Schleef J. Lymphangiomas of the head and neck in children. Acta Otorhinolaryngol Ital. 2008;28:17-20.

6. Rebuffini E, Zuccarino L, Grecchi E, Carinci F, Merulla VE. Picibanil (OK-432) in the treatment of head and neck lymphangiomas in children. Dent Res J (Isfahan). 2012;9:S192-6.

7. Torres-Palomino G, Juárez-Domínguez G, Méndez-Sánchez L. Escleroterapia en malformaciones linfáticas infantiles: revisión sistemática de la literatura. An Med. 2014;59:127-32.

8. Ogita S, Mejía M, Sánchez J. OK-432 PICIBANIL [Internet]. Linfangiomas. Available at: http://linfangiomas.com/default.htm.

9. Lackner H, Karastaneva A, Schwinger W, Benesch M, Sovinz P, Seidel M, et al. Sirolimus for the treatment of children with various complicated vascular anomalies. Eur J Pediatr. 2015;174:1579-84.

10. Mejía M, Sánchez J, Reyes R, Lezama P, Ogita S, Bracho E, et al. Tratamiento de linfangiomas con OK432 (Picibanil). Arch Inv Pediatr Mex. 2005;8:5-9.

11. Santana C, Ambriz G, Ramirez E, López S, Torres E. Experiencia con el uso de OK-432 para el tratamiento de malformaciones linfáticas en niños. XLVIII Congreso Nacional de Cirugía Pediátrica; 2015. 